\title{
Submissions of a Teacher by Modern Russian Pupils
}

\author{
Elena A. Azarova*
}

Galina N. Zhulina

Natalia N. Mozgovaja

Elena N. Novokhatko

Elena G. Shevyreva

Southern Federal University, Rostov-on-Don, Russian Federation; *Corresponding Email: gold-rostov@mail.ru

\section{Doi:10.5901/mjss.2015.v6n6s7p18}

\begin{abstract}
Special attention is paid to the problem of academic motivation both in the Russian, and foreign pedagogical psychology. Importance of its decision is defined by the reason that academic motivation represents a determinant efficiency factor of educational process. The provisions of activity theory of psychological content, functions, mechanism of formation and functioning of motives are the methodological basis of studying of this problem. Authors assume that the important factor connected with motivation of schoolchildren is the personality of a teacher, his professional and personal qualities. In the educational system the issue over how an interest of schoolchildren in the teacher or in his discipline is formed, is always urgent. If the personality of a teacher is interesting, and attractive, he can create also an interest in the discipline. However, if the discipline is initially interesting for the pupil, but the teacher causes negative emotions, the motivation of the schoolchildren starts changing towards decreasing. Ideas of a good teacher of teenagers with different level of academic motivation have become the scope of our research.
\end{abstract}

Keywords: motivation studies, adolescent pupils, high school students, teacher personality.

\section{Introduction}

Close attention is paid to the problem of study motivation in the domestic educational psychology. The importance of its solving is determined by the fact that the study motivation is a decisive factor in the educational process. The methodological basis of research of this problem is the principals of the activity theory about the psychological content, functions, mechanism of formation and functioning of motives. The implementation of the activity approach is the possibility and the necessity of research of the study motives as a structural element of the study activities, formed in the process of its implementation.

Psychological and pedagogical concepts of study motivation are presented in the works of Ksenzova (2005), Lukyanova and Kalinina (2004), Markova (1993), Matyukhina (1984). Ksenzova (2005) offers technologies to ensure the success in the teacher-student system. Markova (1993) who developed models of pedagogical activity and personality of the teacher, offers a definition of academic motive, which reflects the specific nature of the latter. She also identifies two groups of psychological characteristics (criteria) of academic motives: content-related and dynamic. Typology of academic motivation levels, program of its study introduced by Markova (1993), is an important step in the development of issue. Matyukhina (1984) offers to characterize the motives according to the two main lines (criteria): content (direction) and state (development level).However, change of the social situation in the society, new requirements to the pupils' competence, curriculum change and other reforms in education actualize the research of this issue in the new conditions.

The distinguishing features of a modern Russian teacher are constant self-improvement, self-criticism, erudition, and professional excellence.

The present-day economic conditions of the fast-changing Russian society impose exacting requirements on a person, who makes his or her social, moral, and professional choice. A teacher being a bearer of universal human and national values, a wide range of professional competences and human personality is destined to help such a person. The developing and advancing Russian school needs a competent teacher mastered professional knowledge of an educator 
and a schoolmaster, a school guidance counselor and a behavioral therapist.

Under the current conditions of the Russian society development due to permanently changing conditions of life, we often find ourselves in a situation of uncertainty. In order to become successful in their life pupils must not only gain knowledge, skills, and experience, but also learn to use them in their future activity, independently solve their problems. A teacher, who can teach these skills must have a proactive approach to life, be able to analyze one's behavior and emotions, be gender-tolerant, implement creative approach in educational work, not be afraid of using modern computer technologies, be sociable, stress-resistant, mobile, take care of one's physical and psychological health, not be afraid of changing his or her image, dress with elegancy, etc. (Dodonov, 1989)

Nowadays a modern teacher cannot ignore the process of globalization. The reason of the world globalization is the universal process of the society IT penetration. Just a modern teacher must teach information procession, must settle practical issues, interact with other people, and understand the sense of changes in the society, use information technologies.

Knowing about all special aspects of pedagogical process at school a teacher has also not to intrude his (her) pupils' personal field. It is difficult to do so by reason of the difference between their individual and personal characteristics. The personal fields of both parties are present in the "teacher-pupil" interaction system. The personal fields of a pupil and a teacher are extended and filled with new content in the process of pedagogical interaction, establishment of interpersonal relations both positive, and negative, and in the educational structure of school. In this case a teacher realizing his (her) need of being an individual in his (her) turn forms a pupil's relevant demand. Undoubtedly, such abilities show how much a teacher is a professional in his (her) communication with children and how much he (she) can build up relationship based on trust and tolerance with them (Mozgovaya, 2002; Azarova, 2008).

It is also important for a school teacher not only to organize the process of communication for the purpose of knowledge transfer, but also to demonstrate communicative abilities, skills, artistry, charm, and emotionality of real-life communication. It is very important to develop pupils' communicative skills, increase their communicative competence, because this, in its turn, will improve cognitive capabilities, will teach them to acknowledge their mistakes, spare classmates' and other people's vanity, defuse emotional tension, be a tolerant and easy-to-communicate of person (Kotova \& Shiyanov, 1997).

\section{Research Methods}

Analysis of the relevance of the research and determination of objective conditions allowed formulating the research objective - studying peculiarities of a good teacher idea of adolescents with different levels of study motivation.

To prove the proposition that adolescents with different levels of study motivation have the idea of a good teacher according to particular features and differences, a plan of research was developed:

1. In the first step, pupils were offered a questionnaire by M.I. Lukyanova «Methodology of research of study motivation among upper-form pupils». It allowed identification of four groups of respondents by level of educational motivation.

2. In the second step, respondents were proposed to write a mini-essay 'My idea of a good teacher'. An analysis of the works content was carried out (Lukyanova \& Kalinina, 2004)

3. At the third phase there was mathematical processing of the results. For processing of the received results, statistical methods were used: content analysis; $\varphi$ - Fisher's criterion; Spearman correlation analysis.

The research was conducted on the basis of a Novocherkassk school of general education (Russia). The research involved adolescents (age 13-14) in the number of 60 people.

\section{Analysis Result}

On the basis of the results of M.I. Lukyanova's questionnaire the following 4 groups under consideration were formed:

The $1^{\text {st }}$ group - a very high level of learning motivation of $4 \%$ of respondents

The $2^{\text {nd }}$ group - a high level of learning motivation of $53 \%$ of respondents

The $3^{\text {rd }}$ group - a mean level of learning motivation of $21 \%$ of respondents

The $4^{\text {th }}$ group - a reduced level of learning motivation of $22 \%$ of respondents.

Similar distribution is explained by the current trends of pupils' academic motivation development. A reduced level can be explained by reduction of cognition interest, commercialization of study in institutes, absence of understanding of the reason of being a man of education. Undoubtedly, not only a school, but also a family plays a part in it. Very few respondents have a very high level of motivation. It can be also explained by the availability of the main reasons forming 
motivation in whole. As theoretical analysis shows, learning motivation is a sum total of many reasons, some of which are the main reasons, and the other reasons recede into the background.

At the second stage we have undertaken a study of concepts of a good teacher in the groups formed. The method of writing a mini composition has its advantages. By means of a composition teenagers can express the things, which are close to them. The language of a composition translates feelings and thoughts more openly and sincerely. In the process of writing a composition stress rising in case of study is relieved. The age of adolescence (13-14 years) was chosen not by accident, because in accordance with the opinion of many researchers this age is the most demonstrative. In this period pupils' basic concepts of life, themselves, other people, right and wrong are formed, moral evaluation of other people's behavior, an event, a group of people and government is made. The most part of adolescences are on the position of rebelliousness. They keenly feel injustice, lie, and fraud that is why their vision expresses their attitude to the concept more or less sincerely.

After the completion of our work we processed the obtained data by means of frequency analysis and analysis of content (method of revelation and evaluation of special features of tests and other information media (answer to an open question, in which according to the purposes of the studies certain sense bearing units of the content and the form of information are specified) (Bogomolova \& Stefanenko, 1992).

Due to the analysis of theoretical material concerning the chosen issue, consideration of the principles of content analysis, and choice of the existing criteria of a good teacher we have managed to form groups of semantic constructs presented in the respondents' works. The works were subjected to quantitative and qualitative analysis. Frequency of the characteristics occurrence was calculated for all the works.

First, we subjected all the works to frequency analysis and revealed all the semantic constructs used by the respondents in their works. Then basing on the available studies we distributed them by attributes, characteristics, etc. We distributed all the statements by groups of these characteristics. As a result we calculated the frequency of occurrence of these characteristics in all the works. Therefore, a picture of the system interesting for our study and containing the system of adolescents' concepts of a good teacher was formed.

For the purpose of sense bearing units determination 3 experts were involved. As a result of the experts' work we left the sense categories found by the all three experts. The phenomenon of a good teacher and professional is multisided. It has different composition elements, senses, and interpretation. In many works, as well as in scientific literature, a good teacher is appropriated certain universality, and it is written about universal human moral qualities, principles, abilities, and skills. However, to our opinion, taking into consideration the substantially individual sense of this concept it can be universal, because every teacher has his (her) unique qualities, which form his (her) individual portray and style, peculiar properties making him (her) different from other people, the qualities, for which pupils respect and love him (her). For some teachers such qualities are strictness and fairness, for other teachers these are emotionality, sociability, ability of organizing pupils for joint learning activity. Some teachers can perfectly present material and find approach to every pupil. It is impossible to specify all the particularities. However, there are several qualities, without which one cannot work as a teacher. These qualities are love for children, love of their subject, as well as professional knowledge and skills.

Due to the preliminary theoretical analysis of literature, without which it is impossible to carry out psychological analysis of the obtained results, and due to the work of the experts we were able to point out the following characteristics in the respondent's compositions listing them in the order corresponding to the frequency of each characteristic occurrence.

Personal characteristics -254

- Love for children, need and ability of giving heart to them (45)

- Intelligence, intellectual culture (41)

- A man of merry nature, not evil, a good, kind person (39)

- Literacy, individuality, self-dependence (33)

- A high level of common culture and morality (28)

- Physical and mental health (24)

- Attractive (22)

- Sociable (22)

Personal qualities almost in all the respondents' works interspersed with professional qualities. It means that to the pupils' opinion, a person working as a teacher must be a professional in his (her) area. Furthermore, a teacher must have such human qualities, which we cannot always find in other people. For example:

"a good teacher must necessarily be a kind, not evil, cheerful, and merry person giving light to everybody, 
close to whom there are always many pupils";

"a good teacher is always in the center of attention, pupils tag along behind him (her), we do so in our school, if we like a teacher";

"a good teacher is a person, who loves children and people";

"a good teacher is a good man, but he must study to teach a subject", etc.

Professional characteristics -355

- mastering teaching methods (53)

- high professionalism (51)

- love of a subject being taught (49)

- can communicate with people as a professional (43)

- special knowledge, abilities, experience, and skills regarding the subject taught (specialty) (32)

- qualities, which determine the specificity of a teacher's profession; professional patience (29)

- ability of compensating a pupil's weal spots basing on a pupil's capacity (27)

- ability of giving questions at any stage of study (25)

- job performance (23)

- self-educating person (23)

In the respondents' works it was expressed as follows:

"ability of explaining the topic well, answering the questions: a good teacher always asks, if anything is not clear to anyone",

"a good teacher is not only a person, who studied well at the institute, but also a person, who self-educates constantly, reads a lot, and can share with his (her) pupils his (her) knowledge not only on his (her) subject, but also on life as a whole",

"a good teacher always knows the answer to the question, will always support a pupil, will not disgrace a pupil publicly, if the pupil has some trouble, and will not praise the pupil a lot in order the other pupils not feel themselves stupid", etc.

Therefore, a teacher's professionalism and education are the qualities, which are made the corner-stone by pupils.

Socio-pedagogical characteristics - 205:

- gives good marks (23)

- has an ability of hearing pupils(45)

- social responsibility (41)

- teaching tact (39)

- sense of duty and fairness (38)

- desire and ability of working together with other people (21)

- skills of pedagogical communication, ability of finding a common language with pupils, colleagues, and parents (18)

The particularities, which the respondents pointed out as common and universal, we have designated to the category of socio-pedagogical characteristics, i.e. the characteristics regarding the ability of working and communicating in the society, in such a social environment like a school and school collective including not only pupils, but also teachers and parents. Any activity in such an environment and such a space having intense human factor always requires pedagogical skills as such, ability of making contact, organizing interaction, listening, communicating, drawing conclusions, organizing audience and controlling it. All these qualities are based on a desire of working with people, in collective.

A good teacher is always fair minded and tactful. He (she) does not humiliate or abuse pupils. The main thing, in which his fairness and tact are expressed, is a mark. By means of a mark a teacher can cheer a pupil and inspire him (her) for study, encourage or punish him (her). If a pupil works not enough, a teacher feels that knowing the pupil's capacity and can regulate the process of his (her) study by means of a slightly leveled down mark. A mark is an instrument of influence and motivation. Pupils, as a rule, are very sensitive to marks and understand them as evaluation of their personality. That is why for some of them, especially sensitive, this is the main indicator of a teacher's being good or not. But this approach, as well as the argument of a teacher's being good or bad is rather superficial and is the indicator of a pupil's knowledge's and his (her) psychology's being superficial.

In accordance with the results of mini compositions in the group with a very high level of academic motivation (4\%) we can specify the particularities of adolescents' concepts of a good teacher distributing them as follows. Figure 2 


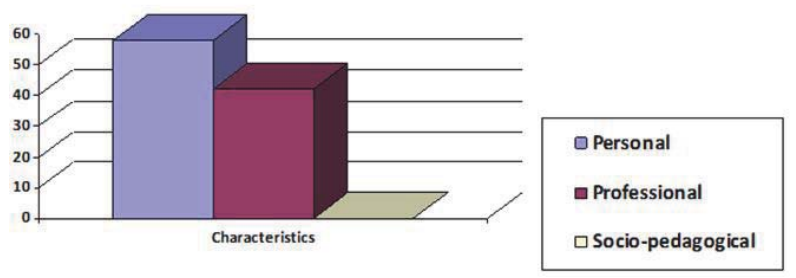

Figure 2. The relations between personal, professional, and socio-pedagogical characteristics in the compositions of pupils having a very high level of academic motivation

Any significant difference in the frequency of occurrence of different personal and professional characteristics is not revealed. For pupils having a very high level of motivation a teacher must have in equal measure a wide range of both professional and personal characteristics of a high quality.

A good teacher is a person mastering teaching methods, having a high level of professionalism, who likes his (her) subject, has special knowledge, skills, and abilities concerning the subject, being able to communicate as a professional, that is why he (she) can be given a question at any stage of study. However, a good teacher is not only a person having a high level of professional qualities, but also a good, kind, and sociable person, who loves children.

In the group of pupils having a high level of motivation (Figure. 3) any significant difference in the frequency of occurrence of different personal and professional characteristics of a "good" teacher is not revealed, but they have psychological difference. It was pointed out in this group, that a good teacher must have professional patience, performance capacity and must strain after self-education. A "good" teacher must be physically and psychically healthy, and attractive.

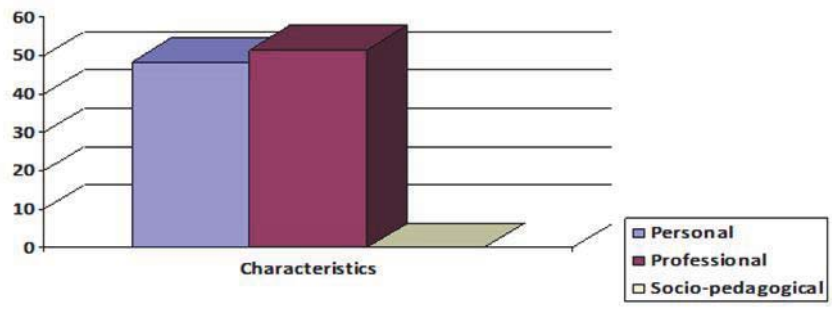

Figure 3. The relations between personal, professional, and socio-pedagogical characteristics in the compositions of pupils having a high level of academic motivation

A high level of academic motivation of such number of pupils is a sufficiently good indicator. Perhaps, these pupils strain for self-education and working capacity, as well as well understand that a teacher needs patience for work with pupils and communications with colleagues. The pupils of the first group did not point out these factors considering that they themselves work well that is why a teacher has not any problem with them and does not need patience. Self-education and working capacity could be implied as components being a part of "love of a subject" and "mastering special knowledge under a subject" indicators.

On the basis of these data it is possible to give a definition of a good teacher from the point of view of pupils having a high level of academic motivation.

A good teacher is a teacher having a high level of professionalism, who likes his (her) subject, has special knowledge, having professional patience, working capacity, and straining after self-education. A good teacher loves children; he (she) is an intelligent, cheerful, sociable, physically and psychically healthy and attractive person.

In the group of pupils having a mean level of academic motivation socio-pedagogical characteristics occur together with professional and personal characteristics. The following scheme of semantic constructs is built up (Figure 4). 


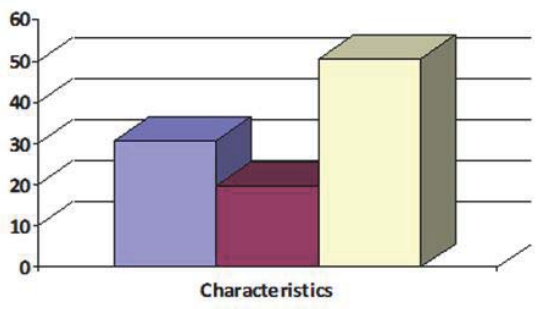

\section{$\square$ personal \\ $\square$ professional \\ $\square$ socio-pedagogical,}

Figure 4. The relations between personal, professional, and socio-pedagogical characteristics in the compositions of pupils having a mean level of academic motivation

Authentically significant differences have been revealed only in the frequency of occurrence of socio-pedagogical characteristics. Therefore, we should say that the most important thing for pupil having a mean level of motivation is a teacher's paying as much as possible attention to pupils, giving them good marks, talking to them about unrelated matters, i.e. creating comfort environment for study process without study.

Thus, a good teacher for this group is a teacher giving not bad marks, able to listen to a pupil, responsible, tactful, fair, and able to find a common language with his (her) pupils, colleagues, and pupils' parents. He (she) likes his (her) subject, everybody can give him questions. He (she) is patient and compensates weak point of a pupil, because he (she) loves children. He (she) is a kind, not evil, physically and psychically healthy person.

In the group of pupils having a reduced level of academic motivation an extremely little number of attributes of professional characteristics is an innovation (Figure 5). Pupils having a reduced level of academic motivation are interested a lot neither in a subject itself, nor in the fact of a teacher's knowledge in the area of this subject and in the teacher's professional skill. Authentically significant differences have been revealed in the frequency of using sociopedagogical and personal characteristics. Therefore, we can say that the image of a "good" teacher for pupils having reduced academic motivation consists of personal and socio-pedagogical characteristics. That means that according to their concept a teacher must be a good person providing comfortable environment for them at school. They need good marks, love, and a teacher's being fair and tactful.

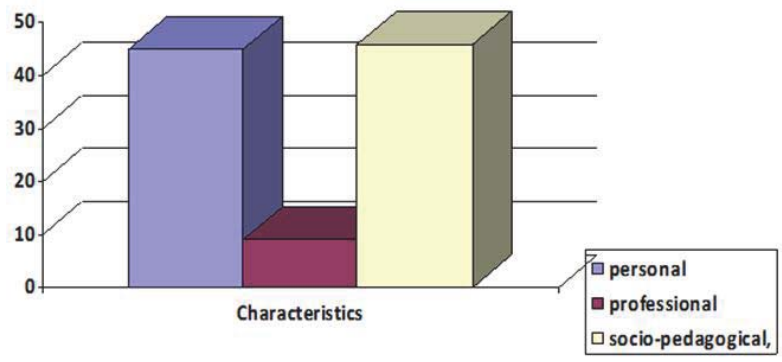

Figure 5. The relations between personal, professional, and socio-pedagogical characteristics in the compositions of pupils having a reduced level of academic motivation

Then we have compared the data on 4 groups of respondents. With the purpose of revealing authentically significant differences in the concepts of a "good" teacher of pupils having different levels of academic motivation we have carried out statistical processing of the received data using Fisher's $\varphi$-ratio test (Table 1.). In order to receive more differentiated data we have compared three pointed out semantic categories between all the groups of pupils pair-wise (Figure 6). 
Table 1. Frequency of using different characteristics in the compositions of pupils having different levels of academic motivation (\%)

\begin{tabular}{lccc}
\hline Groups & Professional characteristics & Personal characteristics & Socio-pedagogical characteristics \\
\hline Very high level of motivation & 57.89 & 42.11 & - \\
High level of motivation & 51.46 & 48.54 & - \\
Mean level of motivation & 19.59 & 30.73 & 50.68 \\
Reduced level of motivation & 9.18 & 44.89 & 45.92 \\
\hline
\end{tabular}

\section{Conclusion}

The carried out theoretical, mathematical, and psychological analysis of the received results has allowed making the following conclusions: We suppose that a good teacher is also a successful teacher. The character of interactions within a high-school educational programme in many respects depend on a teacher, on his (her) ability of receiving and using relevant information on the peculiarities of mental activity and children's condition. It is possible only if a teacher deepens into the psychology of pupils' behavior and their motivation. In this case not separate function of a child, but the child's personality as a whole must be involved in the process of interaction. A situation of not intruding a pupil's and a teacher's personal field within the territory of a school, during classes, is, on the one hand, a condition encouraging the personal fulfillment and self-actualization of a pupil and a teacher, and on the other hand the process of self-actualization itself will facilitate the formation of the personal field of both parties of this process.

Thus, we compared the data of four groups of respondents to identify significant differences in the idea of a "good" teacher by pupils with different levels of study motivation. Next we conducted statistical analysis of the data using $\varphi$ Fisher criterion.

For a fact, pupils with very high, high and reduced motivation for studying use personal characteristics when describing a "good" teacher. At the same time, for pupils with an average study motivation it is not peculiar to emphasize the personal characteristics of a "good" teacher.

Pupils with very high and high levels of study motivation pay particular attention to the professional qualities of the teacher, considering them fundamental at the evaluation of the teacher as "good", along with his/her personal qualities.

Authentically significant differences in the frequency of using social and educational characteristics at the description of the idea of a "good" teacher were found between pupils with very high and high levels of study motivation and between pupils with an average and reduced level of motivation. This proves the prevalence of social and educational characteristics in the groups with sufficiently low motivation of pupils, for whom the matter of the first importance is "convenience" of the teacher.

As a result of the correlation analysis there are significant relationships both between the different characteristics of the teacher and between the study motivation and some of characteristics. There is a significant positive correlation between the frequency of occurrence of personal and professional characteristics $(r=0,646$ at $p=0.01)$ indicating the growing importance of personal characteristics at increasing professional ones and vice versa. Also, there is a negative relationship between the professional and social and pedagogical characteristics $(r=-0,729$ at $p=0.01)$, i.e., the more attention a pupil pays to the professional qualities of the teacher, the less he/she is interested in the social and pedagogical characteristics of the teacher and vice versa.

Two important relationships were also revealed: positive relationship between the level of study motivation of pupils and the frequency of using professional characteristics $(r=0.098$ at $p=0.01)$; negative correlation between the level of study motivation and the frequency of occurrence of social and educational characteristics $(r=-0,553$ at $p=$ $0.01)$.

The received data suggest that at the growth of a child's study motivation in the image of a "good" teacher, the number of professional characteristics is increasing and the number of social and educational skills is reducing. Therefore, we can say that the higher the level of professional and personal features of the teacher, the higher the motivation of study, and vice versa, the higher the study motivation, the more attention pupils pay to professional and personal characteristics.

The less the teacher pays less attention to the educational process and the more focuses on reasoning and abstract topics, the less is study motivation. Conversely, pupils with low study motivation believe that a good teacher is "convenient" for them, does not disturb them by the study process, and is cheerful, sociable and attractive.

Semantic constructs of pupils about the good teacher are presented by personal, professional, social and pedagogical characteristics. 
In the group of pupils with a very high motivation, a "good" teacher is the one who masters the methods of teaching, has a high level of professionalism, loves the subject, has special knowledge, abilities and skills in the subject, is able to communicate professionally, so he/she can be asked questions at any stage of study. He/she is a good, kind, sociable person loving children. No significant differences in the incidence of personal and professional characteristics were revealed.

In the group of pupils with a high level of motivation, a "good" teacher has a high level of professionalism; he/she loves the subject and has special expertise, professional patience, works hard and strives to self-education. A good teacher loves children, he/she is intelligent, cheerful, sociable, healthy (physically and mentally), visually attractive." There were no significant differences in the frequency of characteristics of a "good" teacher "in the works of pupils with a high level of study motivation, but they have psychological differences.

In the group of pupils with an average level of motivation, a "good" teacher gives good marks, is able to listen to a pupil, is responsible, considerate, fair, able to find a common language with pupils, colleagues and parents. He/she loves the subject, can be asked questions, has patience and compensates weaknesses of a pupil because of loving children, being good, non-evil, physically and mentally healthy." Authentically significant differences were found in the incidence of social and educational characteristics. Therefore, for pupils with an average level of study motivation it is important that the teacher pays maximum attention to pupils, puts them good marks, talks with them on abstract topics, etc. That is, the teacher is to create a comfortable environment for the flow of the study process without studying.

The group of pupils with lower levels of motivation is not very interested in neither the subject nor the way the teacher knows it, nor the teacher's skills. In the first position there are good marks and love for children, at that, the teacher is to be fair and considerate. Here there is an external social focus on compliance with visually appealing moments of study "Do nothing and yet get a positive result". Authentically significant differences were found in the frequency of using of social and educational and personal characteristics. Therefore, we can say that the image of a "good" teacher for pupils with reduced study motivation consists of personal and social and educational characteristics. l.e. the teacher, in their idea, is to be a good person creating a comfortable environment for their existence at school. Thus, the hypothesis put forward at the beginning of the research has been confirmed.

\section{References}

Azarova, E.A., \& Koval, U.B. (2008). Pedagogical anthropology: Psychology. A short course of lectures. Rostov-on-Don. Bogomolova, N. N., \& Stefanenko, T.G. (1992). Content analysis. Moscow.

Dodonov, B.I. (1984) Structure and dynamics of activity motives. Issues of Psychology, 4.

Kotova, I.B., \& Shiyanov, E.N. (1997). Pedagogical interaction. Rostov-on-Don: Publishing house: Rostov State Pedagogical University. Ksenzova, G.Y. (2005). How to ensure the situation of success to teacher and student. Pedagogical Society of Russia.

Lukyanova, M.I., \& Kalinina, N.V. (2004). Psycho-pedagogical performance indicators school: criteria and diagnosis. Moscow: SPHERE Markova, A.K. (1986). Development of interest to learning. Moscow.

Markova, A.K. (1993). Psychology of teacher's labour. Moscow.

Matyukhina M.V. (1984). Academic motivation of younger schoolchildren. Moscow.

Mozgovaya, N.N. (2002). Ideas of the personal field of students of a higher pedagogical education institution. PhD thesis in Psychology. Stavropol.

Zeer ,E.F. (2003). Psychology of professional education. Moscow. 